\title{
Modulation of the Bitter Taste to Reduce Calorie Intake
}

\author{
Hee Man Kim \\ Department of Internal Medicine, Yonsei University Wonju College of Medicine, Wonju, Korea
}

\author{
Article: The bitter taste receptor agonist quinine reduces calorie intake and increases the postprandial release of \\ cholecystokinin in healthy subjects \\ Andreozzi P, Sarnelli G, Pesce $M$, et al \\ (J Neurogastroenterol Motil 2015;21:511-519)
}

If food or materials enter the oral cavity, molecules contact taste receptors in the oral cavity. The bitter taste is mediated $\mathrm{G}$ protein-coupled receptors (GPCR) signaling pathway located in taste bud cells. ${ }^{1}$ Taste receptors are divided into 2 families: type 1 (T1R) and type 2 (T2R). T1R comprises 3 different subunits: T1R1, T1R2, and T1R3. T2R is bound to bitter molecules, whereas sweetness is detected by $\mathrm{T} 1 \mathrm{R}$ and T1R3. Interestingly, these taste receptors were expressed in the gastrointestinal mucosa. ${ }^{2}$ Recent data support that GPCR family has a role of sensors of gastrointestinal luminal contents, and when GPCR family is stimulated, functional responses are initiated through the activation of $G$ protein signaling cascades. $G \alpha$ subunits interact with taste receptors. Among G $\alpha$ subunits, $\alpha$-gustducin is a taste-specific signaling protein. ${ }^{3,4}$ Other $G$ protein $\alpha$-subunits, including $\alpha$-transducin and $\mathrm{Gi}$, participate in bitter taste transduction, and are associated with phospholipase $\mathrm{C} \beta 2$ and a calcium-activated cation channel. ${ }^{5}$

In the gastrointestinal mucosa and enteroendocrine cells, the molecules implicated in taste signaling are expressed. ${ }^{6}$ Enteroendocrine cell lines express bitter-taste receptors and $\mathrm{G} \alpha$-proteins, and bitter agonists increase intracellular calcium ion concentration in enteroendocrine cells. ${ }^{6}$ In the other hand, enteroendocrine cells in the gastrointestinal tract release various gastrointestinal peptides including glucagon-like peptide 1, cholecystokinin (CCK), and ghrelin, which are related to control of food intake. ${ }^{7}$ Glucagon-like peptide 1 is released from the intestinal L cells. CCK is synthesized by I-cells in the mucosal epithelium of the small intestine. Glucagon-like peptide 1 and CCK are anorexigenic peptide hormones. Ghrelin is released by gastric enteroendocrine cells and has a role of an orexigenic gut peptide. Bitter compounds interact with enteroendocrine cells, and then they release these hormones to control food intake. For example, when bitter compounds are combined to T2R, they induce the release of the CCK from mouse enteroendocrine cells. ${ }^{8}$ On the contrary, bitter compounds induce the release of ghrelin in mice, stimulating appetite. ${ }^{9}$

Received: September 2, 2015 Revised: September 12, 2015 Accepted: September 13, 2015

(c) This is an Open Access article distributed under the terms of the Creative Commons Attribution Non-Commercial License (http://creativecommons. org/licenses/by-nc/4.0) which permits unrestricted non-commercial use, distribution, and reproduction in any medium, provided the original work is properly cited.

*Correspondence: Hee Man Kim, MD, PhD Department of Internal Medicine, Yonsei University Wonju College of Medicine, 20 Ilsan-ro, Wonju, Gangwon-do 26426, Korea Tel: +82-33-741-1229, E-mail: loverkorea2009@gmail.com

Financial support: None.

Conflicts of interest: None. 
To overcome these reciprocal reactions of bitter compounds, the authors of an article entitled "The bitter taste receptor agonist quinine reduces calorie intake and increases the post-prandial release of cholecystokinin in healthy subjects" in the current issue of Journal of Neurogastroenterology and Motility, devised an acid-resistant capsule including bitter compounds. ${ }^{10}$ Hydrochloride quinine triggers bitter taste by the activation of several members of T2R family receptors, and was used as a bitter compound in this study. ${ }^{11}$ To prevent release of hydrochloride quinine in the stomach, which could cause increase in ghrelin, hydrochloride quinine was contained in an acid-resistant capsule. The encapsulated hydrochloride quinine reduced calorie uptake by $15 \%$, and was associated with higher CCK levels in blood of healthy volunteers than placebo. This small idea that bitter compounds can reach into small intestine with bypass of stomach may resolve a big problem of reciprocal reaction of bitter compounds, release of both anorexic and orexia peptide hormones. These findings suggest that the enteric-releasing bitter compounds may be a drug for control of calorie intake. Also, the authors showed that hydrochloride quinine did not affect gastric emptying rate, whereas in a study using rats, bitter compounds delayed gastric emptying. ${ }^{12}$ This well designed study with a brilliant idea of capsule provided an important information that bitter compounds can control the appetite by stimulating CCK release from enteroendocrine cells in the small intestine.

In conclusion, this well designed study with a brilliant idea of capsule provided an important information that bitter compounds can control the appetite by stimulating CCK from enteroendocrine cells in the small intestine. The bitter compounds may cause the release of both CCK and ghrelin, which may be strength and weakness according to the action site and the intent of the researchers.

\section{References}

1. Chaudhari N, Roper SD. The cell biology of taste. J Cell Biol 2010;190:285-296.

2. Sternini C, Anselmi L, Rozengurt E. Enteroendocrine cells: a site of 'taste' in gastrointestinal chemosensing. Curr Opin Endocrinol Diabetes Obes 2008;15:73-78.

3. Caicedo A, Pereira E, Margolskee RF, Roper SD. Role of the G-protein subunit alpha-gustducin in taste cell responses to bitter stimuli. J Neurosci 2003;23:9947-9952.

4. Wong GT, Gannon KS, Margolskee RF. Transduction of bitter and sweet taste by gustducin. Nature 1996;381:796-800.

5. Margolskee RF. Molecular mechanisms of bitter and sweet taste transduction. J Biol Chem 2002;277:1-4.

6. Wu SV, Rozengurt N, Yang M, et al. Expression of bitter taste receptors of the T2R family in the gastrointestinal tract and enteroendocrine STC-1 cells. Proc Natl Acad Sci USA 2002;99:23922397.

7. Wren AM, Bloom SR. Gut hormones and appetite control. Gastroenterology 2007;132:2116-2130.

8. Chen MC, Wu SV, Reeve JR Jr, Rozengurt E. Bitter stimuli induce $\mathrm{Ca}^{2+}$ signaling and CCK release in enteroendocrine STC-1 cells: role of L-type voltage-sensitive $\mathrm{Ca}^{2+}$ channels. Am J Physiol Cell Physiol 2006;291:C726-C739.

9. Janssen S, Laermans J, Verhulst PJ, Thijs T, Tack J, Depoortere I. Bitter taste receptors and alpha-gustducin regulate the secretion of ghrelin with functional effects on food intake and gastric emptying. Proc Natl Acad Sci USA 2011;108:2094-2099.

10. Andreozzi P, Sarnelli G, Pesce M, et al. The bitter taste receptor agonist quinine reduces calorie intake and increases the postprandial release of cholecystokinin in healthy subjects. J Neurogastroenterol Motil 2015;21:511-519.

11. Wiener A, Shudler M, Levit A, Niv MY. BitterDB: a database of bitter compounds. Nucleic Acids Res 2012;40:D413-D419.

12. Glendinning JI, Yiin YM, Ackroff K, Sclafani A. Intragastric infusion of denatonium conditions flavor aversions and delays gastric emptying in rodents. Physiol Behav 2008;93:757-765. 